\title{
Numerical modeling of heat transfer in the fixed-matrix regenerator working in the Electric Thermal Storage heating system
}

\author{
Piotr Cisek ${ }^{1, *}$, Dawid Taler $^{2}$, and Grzegorz Cisek $^{3}$ \\ ${ }^{1}$ Institute of Thermal Power Engineering, Cracow University of Technology, 31-864 Cracow, Poland \\ ${ }^{2}$ Faculty of Environmental Engineering, Cracow University of Technology, 31-155 Cracow, Poland, \\ ${ }^{3}$ Department of Telecommunications, AGH University of Science and Technology, 30-962 Cracow, Poland
}

\begin{abstract}
The study presents the concept of Electric Thermal Storage (ETS) central heating system. Thermal Energy Storage (TES) is carried out in the fixed-matrix regenerator. The energy conservation equations, determined for the discharge period of the regenerator operation, are implemented in MATLAB numerical procedures based on the Finite Volume Method (FVM). In the model pressure drops within the system are calculated, both for the airflow through the inner tubes, and between the tubes. The flow distribution calculations show that the assumption of even air flow distribution would not be justified. Subsequently, the values of heat transfer coefficients are determined for the four distinct heat transfer surfaces, for the variable axial coordinate $\mathrm{z}$ and during the time of the system operation. The use of two different criterion equations is considered, for determining the mean Nusselt number $\mathrm{Nu}_{\mathrm{m}}$ for fluid flow through the concentric annular duct, as well as for the local Nusselt number $\mathrm{Nu}_{z}$ calculated for the fluid flow through a circular or noncircular ducts. The most appropriate approach is selected by comparing the calculation results with experimental data. Taking into account the relative error, RMSE, and MAPE values calculated, it may be concluded that the Taler correlation - for non-circular ducts - gives results closer to the experimental data obtained.
\end{abstract}

\section{Introduction}

The presented study is related to sensible heat storage carried out in regenerative heat exchangers, also called as regenerators. Regenerative heat exchangers are classified as fixed-matrix and rotary regenerators. The fixed-matrix or fixed-bed regenerator is a periodic-flow heat transfer device with high thermal capacity matrix through which the hot fluid stream and cold fluid stream pass alternately $[1,2]$. Specific parameters determine regenerators performance, i.e., geometry, thermal and mechanical properties of the solid matrix, working fluid properties, as well as a charge and discharge time-length periods [3].

Surface geometries used for the compact fixedmatrix regenerators are, i.e., quartz pebbles, steel, copper, or lead shots, copper wool, packed fibers, powders, randomly packed woven screens, and crossed rods, among others. Fixed-matrix regenerators application involves both high temperature, $800^{\circ} \mathrm{C}-$ $1100^{\circ} \mathrm{C}$, heat recovery systems [4-6], and lowtemperature applications, like space heating in HVAC installations [7-9].

As shown by Ismail et al. [10], two broad groups of models of heat transfer between the working fluid and the regenerator bed are commonly used. The first group includes models in which the regenerator bed and the fluid is considered as one phase. Therefore they are called single-phase models. The second group comprises of models where the bed and the fluid domains are treated as a separate phase, hence the name - two-phase models. In the second group, three basic models may be distinguished, the Schumann's model, the continuous solid phase model, and the concentric dispersion model, that assumes a thermal gradient in the solid particles [10]

In the paper numerical investigation of heat transfer between fixed matrix and working fluid during cooling period is presented. Thus, heat balance equations for the regenerator's matrix and working fluid domains are derived for the concentric dispersion model. The heat balance equations are formulated for the novel design of fixed-bed regenerator that works as a Thermal Energy Storage (TES) unit in Electric Thermal Storage (ETS) central heating system. The governing system of differential equations with formulated boundary and initial conditions is solved using a Finite Volume Method. In the study, an appropriate correlation for determining heat transfer coefficients is also chosen. The numerical model is verified by comparing the computation results with experimental data.

\footnotetext{
* Corresponding author: cisekpiotr@mech.pk.edu.pl
} 


\section{Test stand}

The heating system with the regenerator that works as TES is shown in Fig. 1. Two periods may be distinguished during the TES unit operation. In the first stage, when the off-peak period of power system load occurs, the regenerators matrix is heated up with lowpriced energy. Twenty four electrical heaters, $500 \mathrm{~W}$ of power output each, are installed in the TES unit bed what gives $12 \mathrm{~kW}$ of power output in total. The charging period is extended during the time to achieve uniform matrix temperature throughout the entire bed. The bed temperature may reach even $700^{\circ} \mathrm{C}$ and is measured in three various cross-sections of the regenerator bed. The test facility is equipped with the plate fin-and-tube heat exchanger, as shown in Fig. 1, being investigated and tested in a broad range of previous papers [11-18].

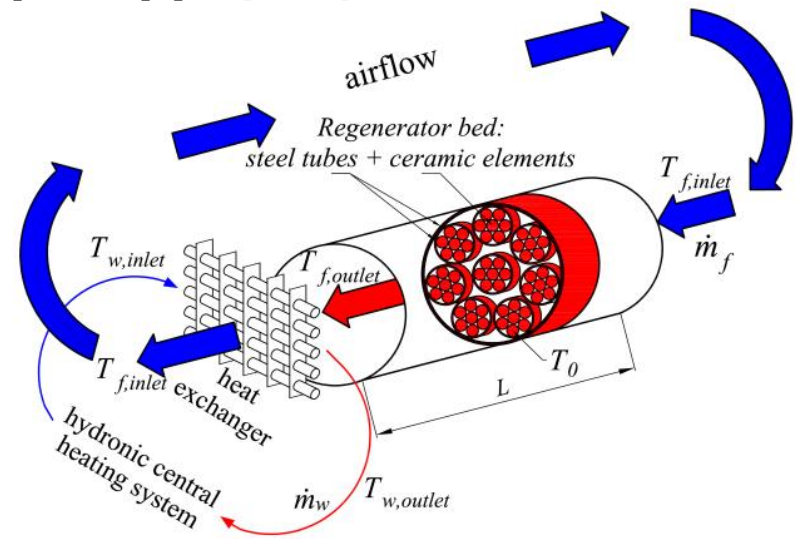

Fig. 1. The central heating system with fixed-matrix regenerator working as a TES unit.

Subsequently, during the discharge period, when electricity price is high (daytime, and on-peak periods), the stored heat is gradually released and used for space heating. Thus, according to Fig. 1, the regenerator matrix is cooled by the air that is circulating in a closed circuit. The centrifugal fan, located at the regenerator inlet section, controls the airflow. When leaving the TES unit, hot air is cooled in the plate fin-and-tube heat exchanger and flows back through the air duct to the regenerator inlet. Hot water, heated up in the heat exchanger, feeds the central heating system which consists of two radiators located in the adjacent room. Thus, in the discharge period, the heat exchanger performs the function of a low-temperature water boiler.

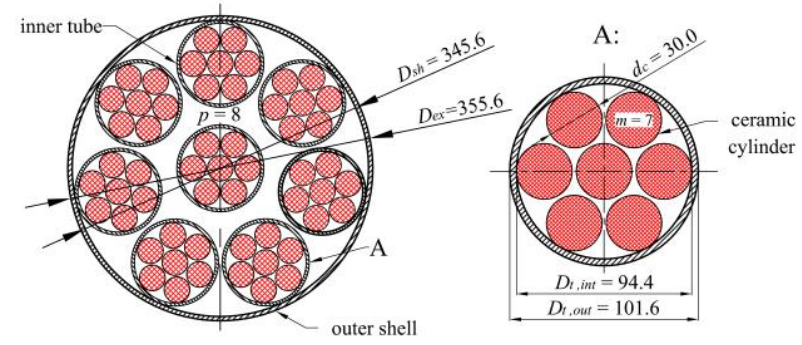

Fig. 2. Regenerator cross-section; all dimensions are given in $\mathrm{mm}$ [19].
The regenerator geometry is shown in Fig. 2. The bed consists of eight steel tubes with the length of $2.0 \mathrm{~m}$ being filled with ceramic cylinders arranged one by one in seven rows in each tube. There are 64 cylinders in one row. The total mass of the ceramic elements is $200,7 \mathrm{~kg}$. The ceramic cylinders of diameter $d_{c}=30 \mathrm{~mm}$ and $30 \mathrm{~mm}$ height, are made of refractory concrete, which thermal properties are as follows: specific heat, $c_{c}=790 \mathrm{~J} /(\mathrm{kg} \cdot \mathrm{K}) ; \quad$ thermal conductivity, $k_{c}=$ $6.4 \mathrm{~W} /(\mathrm{m} \cdot \mathrm{K})$; density, $\rho_{c}=2700 \mathrm{~kg} / \mathrm{m}^{3}$. Other bed parameters may be found in [19].

The experimental setup scheme along with measurement points marked is shown in Fig. 1. The air mass flow rate $\dot{m}_{f}$ is determined using thermal mass flow meter installed in the air duct, while the water mass flow rate $\dot{m}_{w}$ is measured using turbine flow meter installed at the plate fin-and-tube heat exchanger outlet. The air temperatures are measured at the regenerator inlet $T_{f \text {,inlet }}$, and outlet section $T_{f, \text { outlet }}$. The water temperature measurements are carried out both at the heat exchanger inlet and outlet, determining $T_{w \text {,inlet }}$, and $T_{w, \text { outlet }}$ respectively. Temperature measurements are performed using pre-calibrated T-type thermocouples (Cu-CuNi).

\section{Model formulation}

In the previous studies, an analytical solution $[8,20,21]$ and lumped-parameter model [19] of the regenerator bed cooling is presented. The models assumed that the bed is a porous medium, where radial heat conduction is neglected. The two-dimensional model, shown in this study, takes into account the bed geometry. The energy conservation equations are formulated for the solid as ceramic cylinders, steel tubes of the regenerator core and for the outer shell, as well as for the fluid - air flowing in the air gaps across the bed and between the tubes.

When taking into account the simplifying assumptions, that are listed below, the energy conservation equations for the fluid and solid domains may be derived. The following assumptions are made when formulating the model equations:

1. Heat conduction in the air in the axial and radial direction is neglected.

2. Contact between the neighboring solids is neglected so that there is no heat conduction between adjacent ceramics rows as well as between ceramics and steel tubes.

3. Air temperature is a function of time $t$ and axial coordinate $z$ and is uniform at a given regenerator cross-section.

4. Physical properties of the ceramics and steel are considered as temperature independent.

5. There is no heat transfer between the system and the surroundings.

According to the abovementioned assumptions, the heat balance equations for solid and fluid domains are written in the following form: 
for a single row of ceramic cylinders:

$$
\rho_{c} c_{c} \frac{\partial T_{c}}{\partial t}=\frac{1}{r} \frac{\partial}{\partial r}\left(r k_{c} \frac{\partial T_{c}}{\partial r}\right)+\frac{\partial}{\partial z}\left(k_{c} \frac{\partial T_{c}}{\partial z}\right)
$$

where $c$ subscript denotes the ceramics parameter and f,int stands for the air flowing in the inner tubes.

* for the airflow inside the inner tubes, contacting with the ceramic cylinders

$$
\begin{aligned}
\rho_{f} c_{f}\left(\frac{\partial T_{f, i n t}}{\partial t}+w_{f, i n t} \frac{\partial T_{f, i n t}}{\partial z}\right)= \\
=\frac{1}{r} \frac{\partial}{\partial r}\left(r k_{f} \frac{\partial T_{f, i n t}}{\partial r}\right)+\frac{\partial}{\partial z}\left(k_{f} \frac{\partial T_{f, i n t}}{\partial z}\right)
\end{aligned}
$$

where the air velocity inside the inner tubes is denoted as $w_{f, \text { int }}$

* for the steel tubes of the regenerator core

$$
\rho_{s t} c_{s t} \frac{\partial T_{t}}{\partial t}=\frac{1}{r} \frac{\partial}{\partial r}\left(r k_{s t} \frac{\partial T_{t}}{\partial r}\right)+\frac{\partial}{\partial z}\left(k_{s t} \frac{\partial T_{t}}{\partial z}\right)
$$

where subscript $t$ indicates the tubes parameters, and $s t$ stands for steel.

* for the air flowing between the tubes

$$
\begin{aligned}
\rho_{f} c_{f}\left(\frac{\partial T_{f, \text { out }}}{\partial t}+w_{f, \text { out }} \frac{\partial T_{f, \text { out }}}{\partial z}\right)= \\
=\frac{1}{r} \frac{\partial}{\partial r}\left(r k_{f} \frac{\partial T_{f, \text { out }}}{\partial r}\right)+\frac{\partial}{\partial z}\left(k_{f} \frac{\partial T_{f, \text { out }}}{\partial z}\right)
\end{aligned}
$$

Air velocity in the space between the tubes is given as $w_{\text {f,out. }}$.

* for the regenerator outer shell

$$
\rho_{s t} c_{s t} \frac{\partial T_{s h}}{\partial t}=\frac{1}{r} \frac{\partial}{\partial r}\left(r k_{s h} \frac{\partial T_{s h}}{\partial r}\right)+\frac{\partial}{\partial z}\left(k_{s h} \frac{\partial T_{s h}}{\partial z}\right)
$$

The system of partial differential equations, along with boundary conditions, is solved using Finite Volume Method [22, 23]. The primary goal of the calculations is to determine the heat transfer fluid temperature at the regenerator outlet, for the axial coordinate $z=L$, where $L$ is the regenerator length. Input parameters of the model are the total air mass flow rate $\dot{m}_{f}$, air temperature at the inlet section $T_{f \text {,inlet, }}$ and initial temperature $T_{0}$ of the whole bed.

\section{Modeling and analysis}

When determining the airflow distribution within the bed, pressure drop calculations in the system are performed. Basic principles of fluid mechanics state that the fluid flows at a higher rate through the channel, wherein encounters lower pressure drop. In this case, the flow resistance is determined, according to [3], for the subsequent parts of the regenerator, inlet and outlet sections, interior of the steel tubes, and space between the tubes. Based on the estimated pressure drops, it is possible to determine the air flow rates in the inner tubes $\dot{m}_{f, \text { int }}$ and in the space between the tubes $\dot{m}_{f, \text { out }}$ with the constraint that its sum must be equal to the total mass flow rate $\dot{m}_{f}$

$$
\dot{m}_{f}=\dot{m}_{f, \text { out }}+p \dot{m}_{f \text { int }}
$$

where $p$ is the number of steel tubes in the regenerator core, for the considered regenerator $p=8$.

Acquiring information on air distribution is necessary when calculating heat transfer coefficients, and therefore modeling convective heat transfer in the wall-fluid system for the considered bed geometry. An exemplary experimental dataset, collected during the test stand operation, is shown in Fig. 3 and 4. As it is shown in Fig. 4, air flow rate is constant during the system operation. Therefore, for $\dot{m}_{f}=0.07891 \mathrm{~kg} / \mathrm{s}$ values of $\dot{m}_{f, \text { int }}$ and $\dot{m}_{f, \text { out }}$ are calculated, and equals to $\dot{m}_{f, \text { int }}=0.00175 \mathrm{~kg} / \mathrm{s}$ and $\dot{m}_{f, \text { out }}=0.06491 \mathrm{~kg} / \mathrm{s}$ respectively. Thus, less than $17.5 \%$ of the total air flow $\dot{m}_{f}$ goes through the inner tubes. In this case, the crucial role is played by linear pressure losses. The side surfaces roughness of the ceramic cylinders, approx. $0.3 \mathrm{~mm}$, results in significantly higher pressure losses due to the liquid layers friction on the surface of the cylinder. For stainless steel, the roughness value is approx. $0.045 \mathrm{~mm}$.

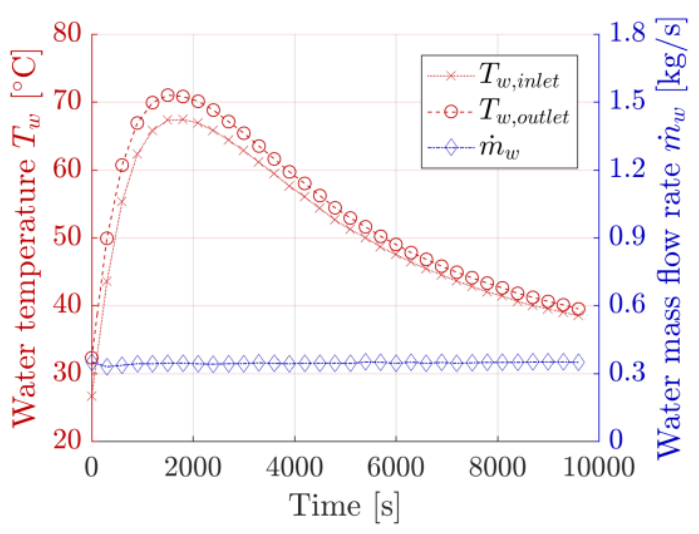

Fig. 3. The water temperature measured at the heat exchanger inlet $T_{w, \text { inlet }}$ and outlet $T_{w, \text { outlet, }}$, along with the water mass flow rate $\dot{m}_{w}$ circulating in the central heating system.

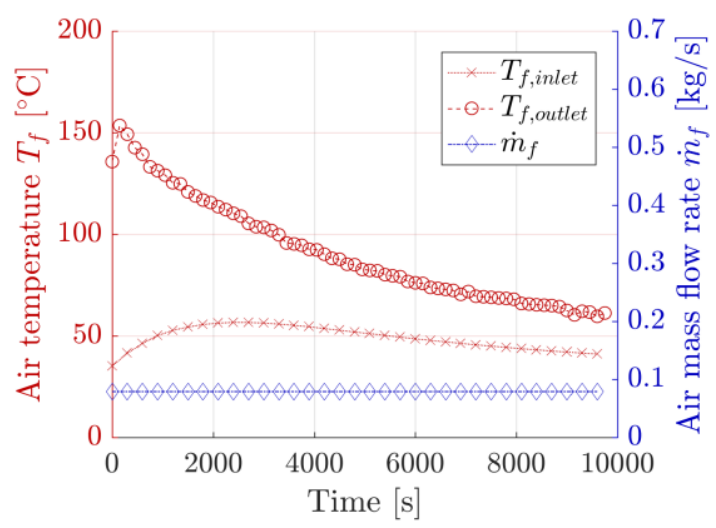

Fig. 4. The air temperature measured at both regenerator inlet

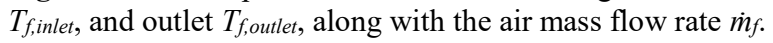

It can be seen in Fig. 4 that at the initial time outlet air temperature $T_{\text {f,outlet }}$ is more than $15^{\circ} \mathrm{C}$ lower than for the next points marked. In this case, a dynamic 
temperature measurement error occurs which is related to the thermal inertia of the thermocouples [24-26].

After determining the flow distribution within the regenerator bed, calculation of heat transfer coefficients is performed. In the study, two approaches for determining the heat transfer coefficients for the air flow through the regenerator bed are compared. The first methodology is presented by Gnielinski in [3]. Herein a chapter devoted to heat transfer in concentric annular ducts may be found. In the second approach, the use of modified Petukhov and Kirillov correlation for the fluid flow through a circular or non-circular duct is considered. The modification is proposed by Taler in $[27,28]$.

\subsection{Heat transfer in concentric annular ducts}

For the case of airflow through the tubes filled with ceramics, it is assumed that each of the cylinder rows is contacting with a ring-shaped air layer of equivalent diameter equal to $35.7 \mathrm{~mm}$. While for the steel tubes in the space between the tubes it is $122.2 \mathrm{~mm}$. The air mass flow rate through the single annular duct is an equal part of the flow rates $\dot{m}_{f, \text { int }}$ and $\dot{m}_{f, \text { out }}$. So that, for the inside of inner tubes, the mass flow rate per a single row of ceramic cylinders is equal to $1 / 7$ of $\dot{m}_{f, i n t}$, and for the single tube it is $1 / 8$ of $\dot{m}_{\text {fout }}$.

In the case of thermally and hydrodynamically developing flow in a concentric annular duct, the mean Nusselt number in the laminar region may be calculated from Martin correlation:

$$
\mathrm{Nu}_{\mathrm{m}, \mathrm{lam}}=\left(\mathrm{Nu}_{\mathrm{m}, 1}{ }^{3}+\mathrm{Nu}_{\mathrm{m}, 2}{ }^{3}+\mathrm{Nu}_{\mathrm{m}, 3}{ }^{3}\right)^{1 / 3} K
$$

where $\mathrm{Nu}_{m, 1}, \mathrm{Nu}_{m, 2}$ and $\mathrm{Nu}_{m, 3}$ are the mean Nusselt numbers, calculated for $\mathrm{Re}<2300$, for boundary conditions specified in [3]. Moreover, $K$ is a correction factor taking into account the effect of changing the fluid physical properties with the temperature

$$
K=\left(\frac{T_{f}+273}{T_{c}+273}\right)^{n}
$$

where the exponent $n$ is $n=0$ when the air is cooling, and $n=0.45$ when it is heated up.

For fully turbulent flow, for $\operatorname{Re} \geq 10^{4}$, the Gnielinski equation for determining the mean Nusselt number during the air flow through the annular duct takes the following form:

$$
\mathrm{Nu}_{\mathrm{m}, \text { turb }}=\frac{\left(\frac{\lambda}{8}\right) \operatorname{Re} \operatorname{Pr}}{k_{1}+12.7 \sqrt{\frac{\lambda}{8}}\left(\operatorname{Pr}^{2 / 3}-1\right)^{2 / 3}}\left[1+\left(\frac{d_{h}}{L}\right)^{2 / 3}\right] F_{a n n}
$$

with

$$
k_{1}=1.07+\frac{900}{\operatorname{Re}}-\frac{0.63}{1+10 \mathrm{Pr}}
$$

where $\lambda$ is a friction factor an annular duct, $\operatorname{Pr}$ is a Prandtl number, and $F_{a n n}$ is a correction factor [3]. Hydraulic diameter $d_{h}$ is a calculated as

$$
d_{h}=d_{o}-d_{i}
$$

where $d_{o}$ is the outer diameter, and $d_{i}$ is the inner diameter of the annuli. In the above equations, the ranges of validity are $10^{4}<\operatorname{Re}<10^{6} ; 0.6<\operatorname{Pr}<1000$; $0 \leq d_{h} / L \leq 1$.

For the transition region between laminar and fully developed turbulent flow, for $2300 \leq \mathrm{Re} \leq 10^{4}$, the mean Nusselt number may be represented by the equation

$$
\begin{array}{r}
\mathrm{Nu}_{\mathrm{m}, \text { trans }}=\left[\left.(1-\gamma) \mathrm{Nu}_{\mathrm{m}, \operatorname{lam}}\right|_{\mathrm{Re}=2300}+\right. \\
\left.+\left.\gamma \mathrm{Nu}_{\mathrm{m}, \text { turb }}\right|_{\mathrm{Re}=10^{4}}\right] K
\end{array}
$$

with

$$
\gamma=\frac{\operatorname{Re}-2300}{10^{4}-2300} \text { and } 0 \leq \gamma \leq 1 .
$$

The drawback of formulae (12) is the adoption of the Reynolds number limit value of $R e=2300$, and $R e=$ $10^{4}$, which marks the boundaries of the transitional flow region. So that, the first derivative $\mathrm{dNu} / \mathrm{dRe}$ in the transition point is no longer continuous. Consequently, when changing the flow region, from the laminar to the transitional, at $\operatorname{Re}=2300$, and from the transitional to the turbulent region, at $\mathrm{Re}=10^{4}$, a rapid change in the course of the function $\mathrm{Nu}=f(\mathrm{Re})$ occurs. For this reason, a new correlation is proposed by Taler [27, 28] that is valid for the transitional and the turbulent flow region.

\subsection{Heat transfer in non-circular ducts}

As the second case, the correlation for determining the local value of the Nusselt number $\mathrm{Nu}_{\mathrm{z}}$ for the fluid flow in the plain tubes is used. The relationship is proposed by Taler [27, 28] for a wide range of Reynolds number values varying between $2300<\mathrm{Re}<10^{6}$. The Taler correlation is a modification of Petukhov and Kirillov equation initially formulated for a turbulent flow range. The coefficients in the Taler equation are determined experimentally by comparing a large amount of experimental data available in the literature. For undeveloped velocity and temperature profiles, assuming a constant wall temperature, the criterion equation takes the following form

$$
\begin{aligned}
\mathrm{Nu}_{\mathrm{z}} & =\left.\mathrm{Nu}_{\mathrm{z}}\right|_{\mathrm{Re}=2300}+ \\
& +\frac{\frac{\lambda}{8}(\operatorname{Re}-2300) \operatorname{Pr}^{1.008}}{1.08+12.39 \sqrt{\frac{\lambda}{8}}\left(\operatorname{Pr}^{2 / 3}-1\right)}\left[1+\frac{1}{3}\left(\frac{d_{h}}{z}\right)^{2 / 3}\right] K
\end{aligned}
$$

The Nusselt number $\mathrm{Nu}_{z \mid \mathrm{Re}=2300}$ in Eq. (14) is calculated from Eq. (15) for $\mathrm{Re}=2300$

$$
\begin{gathered}
\left.\mathrm{Nu}_{\mathrm{z}}\right|_{\mathrm{Re}=2300}=\left[\mathrm{Nu}_{\mathrm{z}, 1}{ }^{3}+0.7^{3}+\left(\mathrm{Nu}_{\mathrm{z}, 2}-0.7\right)^{3}+\right. \\
\left.+\mathrm{Nu}_{\mathrm{z}, 3}{ }^{3}\right]^{1 / 3} K
\end{gathered}
$$

where $\mathrm{Nu}_{\mathrm{z}, 1}, \mathrm{Nu}_{\mathrm{z}, 2}$ and $\mathrm{Nu}_{\mathrm{z}, 3}$ are the local Nusselt numbers, calculated for $\mathrm{Re}=2300$, for boundary conditions specified in [27]. In the equations mentioned above, $\lambda$ is a friction factor a plain tube, calculated from Taler equation [29], $z$ is the axial coordinate, changing 
from 0 to $L$, and $d_{h}$ is the hydraulic diameter calculated as 4 times the flow area divided by the wetted perimeter of the conduit. For $z=0$ is the point from which heating or cooling of the fluid begins. So that, it is a coordinate of the regenerator inlet section.

\subsection{Determination of heat transfer coefficients}

The heat transfer coefficients are determined for the four different contact surfaces:

* $h_{c}$ for the lateral surface of ceramic cylinders;

* $h_{t, \text { int }}$ for the inner surface of the tubes filled with the ceramic cylinders;

* $h_{t, \text { out }}$ for the outer surface of the tubes;

* $h_{s h}$ for the internal surface of the outer shell.

Values of the relevant heat transfer coefficients are determined in the model for each time-step and for each of the $N$ control volumes of the solid body being in contact with the fluid.

Figures 5 and 6 show the time courses of the heat transfer coefficient values determined for various axial coordinates $z$, where $z=0$ is the inlet, and $z=2 \mathrm{~m}$ is the outlet cross-section of the regenerator bed.
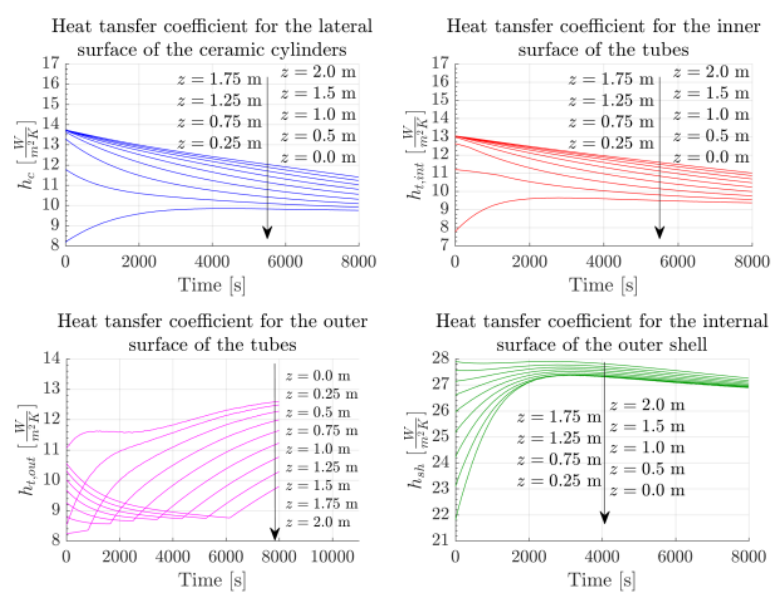

Fig. 5. Values of the heat transfer coefficients, determined for annular duct flow, for the variable axial coordinate $z$ and during the time of the system operation.
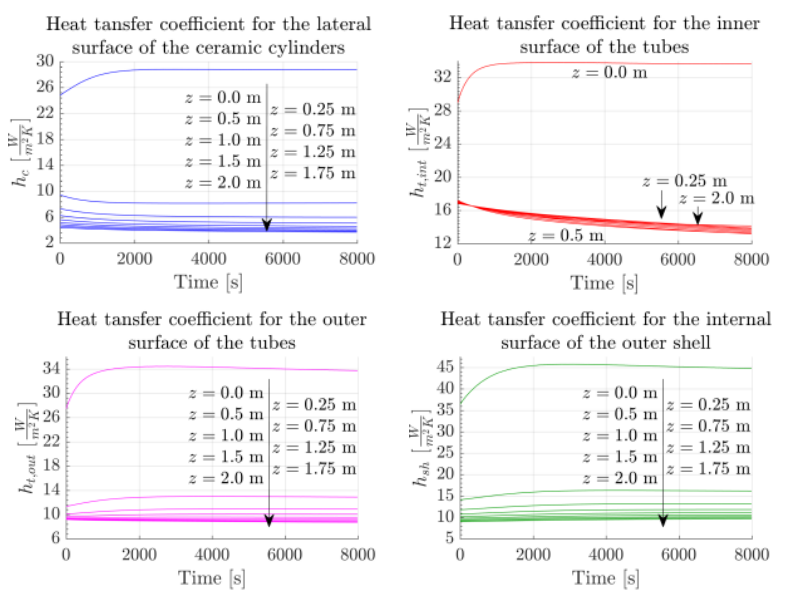

Fig. 6. Values of the heat transfer coefficients, determined for non-circular duct flow, for the variable axial coordinate $z$ and during the time of the system operation.
Figure 5 presents the calculation results when the annular flow is assumed. The $h_{c}$ and $h_{t, \text { int }}$ values are the lowest in the inlet section, for $z=0$, and rises with increasing $z$, reaching the highest values at $z=2 \mathrm{~m}$, so at the outlet section. The results shown in Fig. 6 are entirely different. According to Taler correlation, in the inlet cross-section the highest values of heat transfer coefficients are obtained, which decrease in the range $z=0 \div 0.25$ almost three times, and then set at a similar level. In the inlet section, severe disturbances and changes in the flow direction are expected. Thus, it may result in an intensification of heat transfer until the flow stabilizes. It can be supposed that the $h_{c}$ and $h_{t, \text { int }}$ values obtained in this case are closer to reality.

The time course of $h_{t, \text { out }}$ shown in Fig. 5 reveals the fundamental drawback of averaging the heat transfer coefficient values in the transitional region, according to the Eq. (12). A rapid change in the course of the $h_{t, \text { out }}$ values, may be noticed when changing from transitional to the laminar flow region. As it can be seen in Fig. 6, Taler's approach is free of this drawback.

\subsection{Experimental validation}

Experimental verification of the proposed heat transfer correlations is carried out with comparing the temperature $T_{f, \text { outlet, }}$ obtained from measurements, with mass-average temperature $\left.\bar{T}_{f}\right|_{z=L}$, determined from Eq. (16) for the outlet cross-section of the regenerator, for $z=L$

$$
\left.\bar{T}_{f}\right|_{z=L}=\frac{\left.p \dot{m}_{f, \text { int }} T_{f, \text { int }}\right|_{z=L}+\left.\dot{m}_{f, \text { out }} T_{f, \text { out }}\right|_{z=L}}{\dot{m}_{f}}
$$

where $T_{f \text {,int }}$, and $T_{f \text {,out }}$ are the air temperatures determined, respectively, within the steel tubes, and in the space between the tubes.

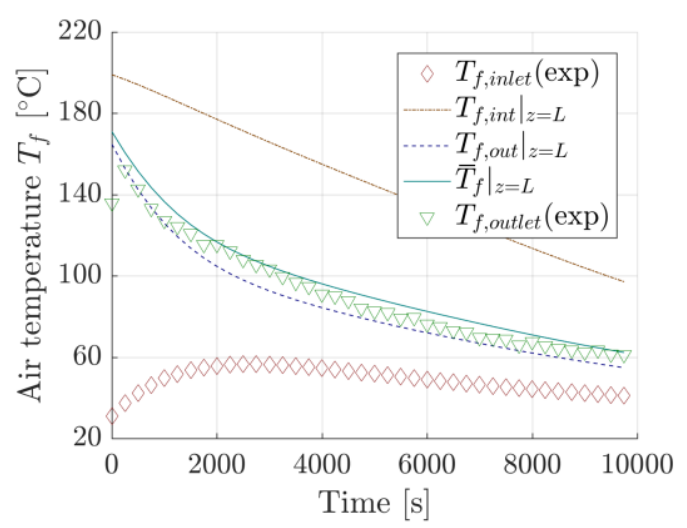

Fig. 7. Calculation results when determining heat transfer coefficients for an annular duct flow - according to Gnielinski.

In Figs 7 and 8, computation results of the air outlet temperature along with its experimental values are presented. To better compare the numerical and experimental results, the relative error is calculated, for each of the time-step number $n$, and for the both considered cases 


$$
\varepsilon_{f}^{n}=\frac{\left.\bar{T}_{f}^{n}\right|_{z=L}-T_{f, \text { outlet }}^{n}}{T_{f, \text { max }}-T_{f, \text { min }}} \cdot 100 \%
$$

where $T_{f, \max }$ and $T_{f, \min }$ are the maximal and minimal air temperatures determined within the system.

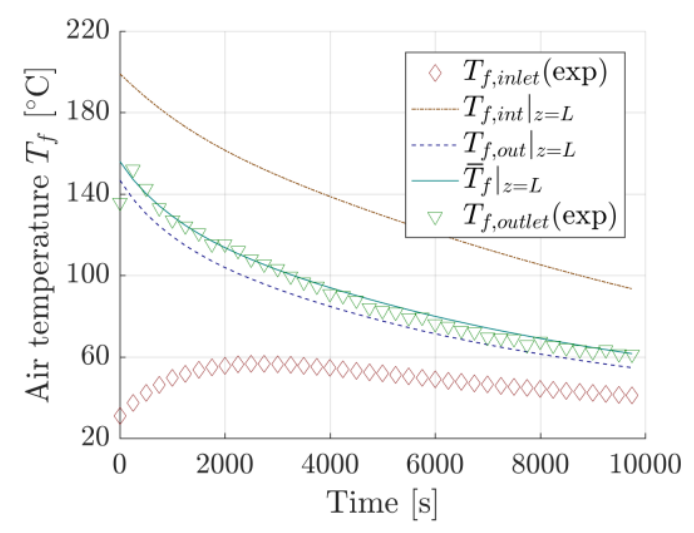

Fig. 8. Calculation results when determining heat transfer coefficients for a non-circular duct flow - according to Taler.

For the uncertainty analysis, the Root Mean Square Error (RMSE) and the Mean Absolute Percentage Error $(M A P E)$ are also calculated

$$
\begin{aligned}
& R M S E=\sqrt{\frac{1}{N_{t}} \sum_{n=1}^{N_{t}}\left(\left.\bar{T}_{f}^{n}\right|_{z=L}-T_{f, \text { outlet }}^{n}\right)^{2}} \\
& M A P E=\frac{1}{N_{t}} \sum_{n=1}^{N_{t}} \frac{\left|\bar{T}_{f}^{n}\right|_{z=L}-T_{f, \text { outlet }}^{n} \mid}{T_{f, \text { outlet }}^{n}} \cdot 100 \%
\end{aligned}
$$

where $N_{t}$ is the total number of time steps.

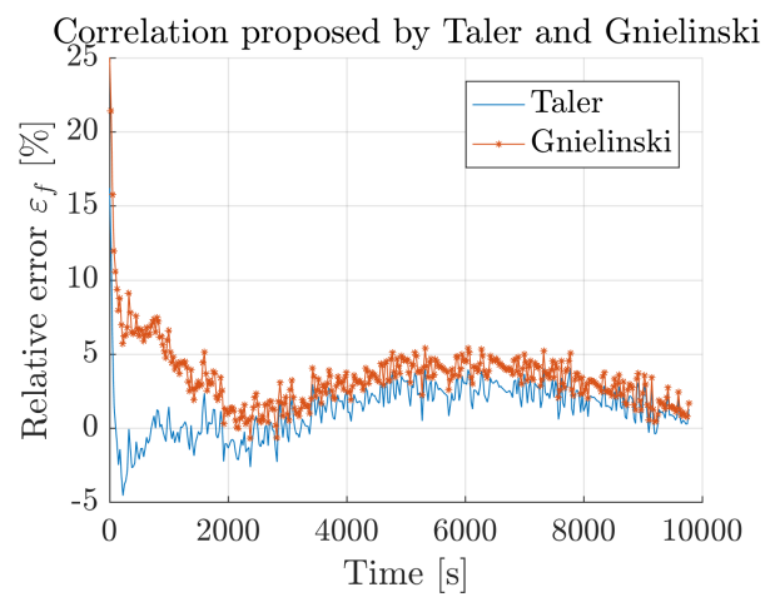

Fig. 9. The values of $\varepsilon_{f}$ determined from Eq. (17) for the results obtained from the model and compared to the experimental ones.

For the results shown in Fig. 7, when using Eqs (7) - (13), RMSE $=5,77^{\circ} \mathrm{C}$, and $M A P E=5,43 \%$. When considering Taler correlation, Eqs (14) - (15), RMSE = $2,71{ }^{\circ} \mathrm{C}$, and $M A P E=2,66 \%$, see Fig. 8 . As it is shown, the RMSE and MAPE values are more than 2 times lower for the Taler correlation. Based on the RMSE and $M A P E$ values, as well as maximum values of the relative error, presented in Fig. 9, it may be concluded, that a good agreement between the experiment and calculation results is achieved when using Taler approach. A significant relative error for an initial time, exceeding $16 \%$ in both cases, is caused by a dynamic temperature measurement error. In the remaining time period, $\varepsilon_{f}$ is not exceeding $\pm 5 \%$.

\section{Conclusions}

The study presents the concept of Electric Thermal Storage (ETS) central heating system. Thermal Energy Storage (TES) in the system is carried out in the fixedmatrix regenerator. In the article construction of the regenerator is presented. The test stand built in the laboratory of the Institute of Thermal Power Engineering at the Cracow University of Technology is used to test the proposed ETS central heating system.

The energy conservation equations, formulated for the two-dimensional model, takes into account the regenerator bed geometry. After the model validation, the developed heat balance equations are implemented in MATLAB numerical procedures based on the Finite Volume Method. In the model pressure drops within the system are calculated, both for the airflow through the inner tubes, and between the tubes. The flow distribution calculations show that in the tubes filled with ceramics flow resistance is much higher than for the flow between the tubes. Therefore, approx. $17.5 \%$ of the total flow rate $\dot{m}_{f}$ goes through the eight tubes filled with the ceramic cylinders. Thus, the assumption of even air flow distribution would not be justified.

Subsequently, the values of heat transfer coefficients $h_{c}, h_{t, \text { int }}, h_{t, \text { out }}$, and $h_{s h}$ are determined for the four distinct heat transfer surfaces, for the variable axial coordinate $z$ and during the time of the system operation. The use of two different criterion equations is considered: first one, proposed by Gnielinski, for determining the mean Nusselt number $\mathrm{Nu}_{\mathrm{m}}$ for fluid flow through the duct of the annular cross-section; the second one is recommended by Taler for the fluid flow through a circular or non-circular ducts. The Taler correlation is further modified for determining local Nusselt numbers $\mathrm{Nu}_{z}$. The most appropriate approach is selected by comparing the calculation results with experimental data. Taking into account the relative error, RMSE, and MAPE values calculated, it may be concluded that better results are obtained in this case for the Taler correlation.

The numerical model may be used in the design and performance assessment of the presented accumulative heating systems. The development of mathematical procedures that allows determining the temperature of the air leaving the TES unit during the time, with the selected parameters of the system, i.e., mass flow rate, number of tubes in the core, shape, and material from which bed particles are made, etc. The numerical procedures may support the design and selection of devices at the planning stage of installation capacity. Moreover, the model may also be useful during the implementation of a model-based control system that is planned to be developed in the future. 


\section{References}

1. D.L. Zunft, Chapter in L.F. Cabeza (Ed.), Advances in Thermal Energy Storage Systems. Methods and Applications (Woodhead Publishing Series in Energy 66, 2015)

2. K. Thulukkanam, Heat Exchanger Design Handbook ( $2^{\text {nd }}$ Ed., CRC Press, 2013)

3. Verein Deutscher Ingenieure VDI-Gesellschaft Verfahrenstechnik und Chemieingenieurwesen (GVC) (Ed.), VDI Heat Atlas ( $2^{\text {nd }}$ Ed., Springer, 2010).

4. Y. Jian, Q. Falcoz, P. Neveu, F. Bai, Y. Wang, Z. Wang, Appl. Energy 139, 30-42 (2015).

5. M.A. Al-Nimir, M.K. Abu-Qudasi, M.D. Mashaqi, Energy Convers. Manag. 37, 23-30 (1996)

6. A. Mawire, M. McPherson, R.R. van den Heetkamp, S.J.P. Mlatho, Appl. Energy 86, 12461252 (2009)

7. P.M. Cuce, S. Riffat, Renew. Sust. Energ. Rev. 47, 665-682 (2015)

8. D. Taler, P. Cisek, Archives of Thermodynamics 4, 55-67 (2013)

9. J. Sacharczuk, D. Taler, Archives of Thermodynamics 3, 281-295 (2014)

10. K.A.R. Ismail, R. Stuginsky Jr, Appl. Ther. Eng. 19, 757-788 (1999)

11. A. Cebula, D. Taler, Archives of Thermodynamics 30, 45-66 (2009)

12. D. Taler, P. Ocłoń, Int. J. Therm. Sci. 84, 309-322 (2014)

13. D. Taler, P. Ocłoń, Chem. Eng. Process. 83, 1-11 (2014)

14. D. Taler, Energy Convers. Manag. 96, 452-462 (2015)

15. A. Korzeń, D. Taler, Int. J. Therm. Sci. 92, 188$198(2015)$

16. J. Taler, P. Ocłoń, D. Taler, M. Nowak-Ocłoń, Chapter in: M. Salim Newaz Kazi (Ed.), Heat Transfer Studies and Applications (InTech 2015)

17. D. Taler, Energy Convers. Manag. 159, 232-243 (2018)

18. D. Taler, A. Korzeń, Int. J. Numer. Method. H. 28 , 81-91 (2018)

19. P.Cisek, D. Taler, Energ. Buildings 130, 747-760 (2016)

20. D. Taler, K. Kaczmarski, J. Therm. Sci. 25, 549557 (2016)

21. D. Taler, K. Kaczmarski, Technical Transactions. Mechanics 1-M, 231-242 (2016)

22. J. Taler, P. Duda, Solving Direct and Inverse Heat Conduction Problems (Springer, 2006)

23. A. Cebula, D. Taler, Chapter in: R.B. Hetnarski (Ed.), Encyclopedia of thermal stresses 4: F-G, 1645-1658 (Springer, 2014)
24. M. Majdak, M. Jaremkiewicz, Measurement Automation Monitoring 62, 284-287 (2016)

25. M. Jaremkiewicz, D. Taler, T. Sobota, Int. J. Therm. Sci. 87, 241-250 (2015)

26. M. Jaremkiewicz, Heat Mass Transf. 53, 887-897 (2017)

27. D. Taler, Int. J. Therm. Sci. 108, 108-122 (2016)

28. D. Taler, Numerical modelling and experimental testing of heat exchangers (Springer, 2019)

29. D. Taler, Int. J. Therm. Sci. 105, 109-122 (2016) 